\title{
The murburn perspective for cellular ionic homeostasis and electrophysiology
}

\author{
Kelath Murali Manoj ${ }^{1}$, Nikolai Bazhin ${ }^{2}$, Hirohisa Tamagawa ${ }^{3}$ \\ (*Corresponding author) \\ ${ }^{1}$ Satyamjayatu: The Science \& Ethics Foundation,
} Kulappully, Shoranur-2 (PO), Palakkad District, Kerala State, India-679122.

Email: murman@satyamjayatu.com (ORCID: 0000-0003-4515-994X)

${ }^{2}$ Institute of Chemical Kinetics and Combustion

Russian Academy of Sciences, St. Institutskaya 3, 630090 Novosibirsk, Russia.

Email: bazhin8999@kinetics.nsc.ru (ORCID: 0000-0002-1048-303X)

${ }^{4}$ Dept. of Mechanical Engineering, Gifu University, 1-1 Yanagido, Gifu City, Japan 501-1193.

Email: tmgwhrhs@ @ifu-u.ac.jp (ORCID: 0000-0003-0532-8278)

\begin{abstract}
Starting from basic molecular structure and redox properties of its components, we build a macroscopic cellular electrophysiological model. We first present a murburn purview that could explain ion-distribution in bulk-milieu/membrane-interface and support the origin of transmembrane potential (TMP) in cells. In particular, the discussion focuses on how cells achieve disparity in the distribution of monovalent and divalent cations within $\left(\mathrm{K}^{+}>\mathrm{Na}^{+}>\mathrm{Mg}^{2+}>\mathrm{Ca}^{2+}\right)$ and outside $\left(\mathrm{Na}^{+}>\mathrm{K}^{+}>\mathrm{Ca}^{2+}>\mathrm{Mg}^{2+}\right)$. We explore how TMP could vary for resting/graded/action potentials generation and project a model for impulse conduction in neurons. Outcomes based in murburn bioenergetic equilibriums leading to solubilization of ionpairs, membrane's permittivity, protein channels' fluxes, and proteins' innate ability to bind/adsorb ions selectively are projected as the integral rationale. We also provide experimental modalities to ratify the projections.
\end{abstract}

Keywords: homeostasis; resting/trans membrane potential; action potential; Hofmeister series; membrane channels; electrogenic pumps; association-induction hypothesis; murburn concept 


\title{
Highlights
}

*Murburn concept postulates that homeostasis and electrophysiology are linked

*Cation retention in bulk milieu is based on paired solubilization with respiratory anions

*Interfacial ion differentiation results due to reactivity/solubilization preferences

*Transduction of diverse signals involves oxygen-superoxide-peroxide equilibriums

*After effective charge separation, equilibration occurs to maintain electroneutrality

*Besides ionic differentials, electron transfer phenomenon also govern the outcomes

\section{Contents}

1. The aspect of life explored herein

2. The approach (ideas and systems) chosen for this explorative study

3. Murbun concept offers a new perspective for cellular homeostasis and electrophysiology

I. Introduction to murburn concept

II. What are the major perceptional changes that murburn concept ushers in?

II. Murburn model for cellular ion distribution

III. Murburn thermodynamics for interfacial cation differentiation

IV. Murburn perspective for TMP (RP, GP \& AP)

$\mathrm{V}$. Experimental projections for ratifying the new proposal

4. Summation

\begin{abstract}
Abbreviations
ADHN- apparent dynamic hydration number, AP: action potential, DR(O)S/ROS: diffusible reactive (oxygen) species, ECS: effective charge separation, GP: graded potential, GSE: Gibbs solvation energy, JDVBC: Jones-Dole viscosity B coefficient, RBC: red blood corpuscles, TMP: trans-membrane potential
\end{abstract}




\section{The aspect of life explored herein}

Terms and concepts in physics are generally mathematically definitive, when compared to their counterparts in biology. Therefore, the definition and demarcation of biological ideas are more a matter of subjective consensus. In this regard, defining a profound concept like life is a daunting task indeed. Horowitz definition of life as anything with 'replicability, mutability and catalytic ability' is definitely a good one. However, as the organized cellular whole manifests qualities greater than the sum of its chemico-physical components, life remains an enigma in the gestalt perspective. Yet, scientists can study the various phenomena of life in differentiated detail at the molecular level (e.g. redox metabolism) or integrated holistically at the macroscopic view (e.g. electrophysiology). Under such a purview, to our understanding, life is built on/around three key biological principles/pillars- (i) Cell/protoplasm theory of composition: cell/protoplasm is the fundamental unit of life; (ii) Capacity for dynamic sustenance: cellular living organisms generate energy to do useful work, homeostasize, respond to stimuli, and possess adaptability for survival with respect to immediate environmental pressures; \& (iii) Central dogma of functional perpetuation: within cells, genes code for proteins and these two (in conjunction with environmental criteria) govern a living being's traits and evolutionary disposition.

This write-up is an exploration regarding the second principle of life: explanations for the physico-chemical foundations of homeostasis and immediate electrophysiological response to stimuli, involving the intricately associated phenomena of trans-membrane potential (TMP). In particular, living beings possess unique abilities to concentrate ions within, and this facet is necessary for discharging the essential/vital functions. As per the prevailing concepts in cell biology, cellular composition/flux is retained primarily due to the functioning of cell-membrane and the embedded proteins therin (Alberts et al., 2002; Berg et al., 2002; Nelson \& Cox, 2004; Voet \& Voet, 2011). We had recently mooted the need for more holistic and accommodative explanations for cellular homeostasis and electrophysiological responses (Manoj \& Tamagawa, 2020). Herein, a simple murburn model is projected to explain the long-standing conundrum of how living cells possess unique abilities to concentrate cations in the distribution order of $\mathrm{K}^{+}>$ $\mathrm{Na}^{+}>\mathrm{Mg}^{2+}>\mathrm{Ca}^{2+}$, from an ab initio perspective (within the erythrocyte model). Building on this model, we also afford a simple strength-duration threshold response and resting-graded- 
action potentials in neuronal (excitable) cells. We provide a minimal phenomenological and thermodynamic treatment here; as the mathematical modeling of the pertinent fluxes and potentials are deemed to exceed the scope of this introductory essay.

\section{Justifying the approach (ideas and systems) chosen for this exploration}

In the multi-cellular organisms, various tissues (comprising of diverse differentiated cells), organs, organ systems, etc. are integrated and 'administered' with genetic cues/controls, cellular messengers, hormonal, neuronal and other mechanistic measures. Regardless of the complexities in reception of stimuli, it can be envisaged that in order to effectively transduce and synchronize various processes and govern life, certain chemico-physical operating principles must function at multiple levels. Herein, we deal with such direct and simple operating principles (sans genetic/neuronal/hormonal intervention) involved in the maintenance (homeostasis) or fluctuations (response to stimuli) of key components' concentrations within cell(s) and discuss the electrophysiological phenomena associated with the same, in two simple model systems. In spite of its enucleated and therefore, non-replicable and immutable features (and thus, failure to meet the criteria of being termed as a fully functional "living cell"), the pseudo-alive erythrocytes or red blood corpuscles (RBC) can be taken as a simple system for understanding homeostasis. Further, the RBCs can be studied in isolation and they don't have complexities introduced by genetic regulations and mitochondrial metabolism. Neurons, although cannot divide, are definitely classified as 'living cells' by all scientists; and these cells are also 'excitable'. In order to deduce and prioritize the key operational principles of homeostasis, we shall peruse the known facts/aspects of the two aforementioned systems. At the very outset, we disclaim that it is merely for the sake of convenience that a distinction is made between homeostasis and response to stimuli. It is quintessential from the laws of physics that the sustenance of life dictates the dynamic maintenance of a "status-quo" (homeostasis) and therefore, it is only consequential that a change results within, in response to perceptible stimuli presented to the living system. That is- homeostasis and electrophysiological responses are interrelated, quite like the action-reaction principle of Newtonian realms. Further, quantitative values 
(whether normal or average) that portray healthy physiology are cited from credible literature. We aim to stick to simple principles of chemico-physics and arithmetic yardsticks in this study.

\section{Murburn concept strives to integrate bioenergetics, cell homeostasis and electrophysiological responses}

Classical metabolic cycles involving enzyme catalyzed reactions (enzyme-substrate interactions), signal cascades (receptor-affector binding) and electron transfers (donor-acceptor pairing) are well-charted and supposed to work through affinity-based topographical recognitions between the protagonists. Murburn concept is a new paradigm that documents diffusible reactive (oxygen) species (DRS/DROS/ROS) mediated moiety and electron transfers that are fundamental to metabolism and consequentially, physiology. While genes and proteins can chart a deterministic mandate for the cell's sustainability, there must also be stochastically favorable natural factors that could work favorably for cell maintenance. Cells can be deemed to work as redox machines, and cellular redox processes are based on electron transfers and equilibriums amongst its component molecules and ions. Murburn concept is a comprehensive view of interactive equilibrium of molecules, ions and spontaneously formed radicals in cell metabolism/physiology (Manoj, 2018b; Manoj, 2020b) (Figure 1). In terms of enzyme catalysis, signal transduction and electron transfers, murburn scheme involves key functions for DRS in affecting/effecting crucial cellular metabolic or physiological outcomes.

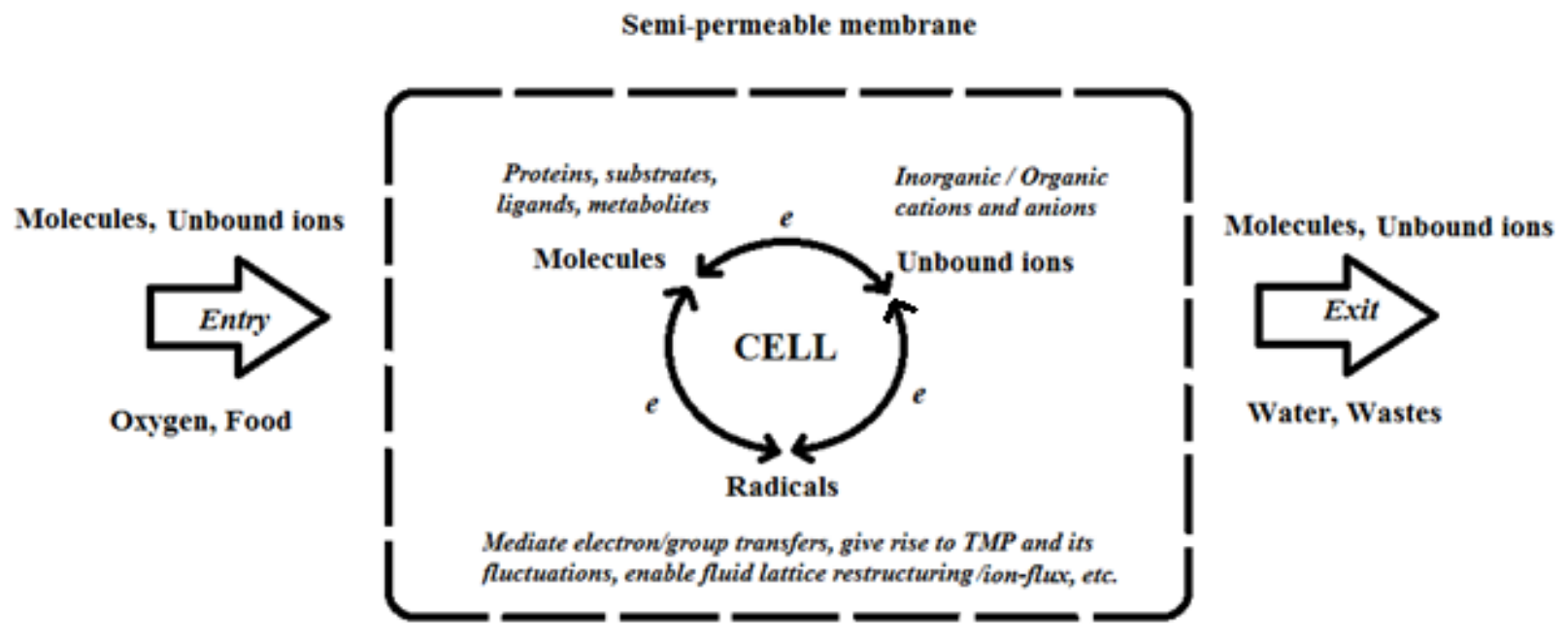


Figure 1: The murburn purview of cellular redox metabolism and homeostasis: Cell is perceived as a murburn reactor which receives the input of several molecules and unbound ions; particularly- food (fuel) and oxygen (oxidant). In the cells, the electrons 'liberated' from food (fuel) are subjected to several equilibriums, involving diffusible reactive (oxygen) species (DROS/DRS/ROS). The DRS produced during murburn enables key signatures of life like TMP, ion-differentials, flux of metabolites, etc.

What are the major perceptional changes that murburn concept ushers in? Till date, murburn concept based de novo explanations were provided for diverse fundamental aspects of life: moiety and electron transfers mediated by heme-/flavin- enzymes (Manoj, 2006; Manoj \& Hager, 2008; Manoj et al., 2010; Andrew et al., 2012; Parashar et al., 2014; Manoj et al., 2016ab; Gideon et al., 2021), aerobic respiration (Manoj et al., 2019a-b; Manoj et al., 2020a; Manoj \& Bazhin, 2021), oxygenic photosynthesis (Gideon et al., 2020; Manoj et al., 2020b,c; Manoj \& Manekkathodi, 2021), xenobiotic metabolism (Manoj et al., 2016c; Parashar \& Manoj, 2021), idiosyncratic/hormetic dose responses (Parashar et al., 2018), homeostasis/trans-membrane potential/thermogenesis (Manoj et al., 2018; Manoj \& Bazhin, 2021), signal transduction in vision (Manoj \& Jacob, 2020), explanations for hemoglobin's role as an ATP-synthase in erythrocytes (Parashar \& Manoj, 2021), etc.

Earlier, it was believed that only topographical recognitions afford selectivity and specificity in biochemical/biophysical processes. With the advent of murburn concept, such an aesthetic perception is no more a 'binding' requisite. This simple perspective change has brought in grassroot level re-interpretation of various key phenomena that support life. In the classical purview, ATP synthesis was seen as a complicated electro-mechanical process involving dozens of proteins whereas the murburn bioenergetic scheme figures it out as a simple bimolecular chemical reaction. While the classical purviews deemed heat production, TMP generation, homeostasis and several electrophysiological processes as independent processes requiring special drives and ATP consumption, murburn concept points out that these are all intricately connected with simple cause-consequence rationale. On a philosophical level, murburn concept shows that DRS (perceived as mere agents of chaos) can also aid significantly in the ordermaintenance within cells! 
Murburn explanation for ion-distribution/retention in bulk cellular milieu: We aim to account for the resting ion distribution found in cells (i.e. ionic homeostasis). The distribution ratio of the four cations $\left(\mathrm{K}^{+}, \mathrm{Na}^{+}, \mathrm{Ca}^{2+} \& \mathrm{Mg}^{2+}\right)$ inside the $\mathrm{RBC}$ was found to be $73: 6.3: 0.003: 1$, respectively (Table 1). When compared with respect to a single ion of calcium, $\sim 2.4 \times 10^{4} \mathrm{~K}^{+}$ and $2.1 \times 10^{3} \mathrm{Na}^{+}$ions are found in erythrocytes! A compilation of miscellaneous features of the cations considered relevant is presented in Table 2.

Table 1: Distribution profiles of the major cations and anions in human erythrocytes.

\begin{tabular}{ccccccccc}
\hline Item & $\begin{array}{c}\mathrm{K}(+) \\
\text { (a) }\end{array}$ & $\begin{array}{c}\mathbf{N a}(+) \\
\text { (b) }\end{array}$ & $\begin{array}{c}\mathrm{Ca}(++) \\
\text { (a) }\end{array}$ & $\begin{array}{c}\mathbf{M g}(++) \\
\text { (b) }\end{array}$ & $\begin{array}{c}\mathrm{Cl}(-) \\
\text { (a) }\end{array}$ & $\begin{array}{c}\mathrm{HCO}_{3}(-) \\
\text { (b) }\end{array}$ & Pi (?) & Protein (?) $^{\#}$ \\
\hline RBC (in) & $139 \mathrm{mM}$ & $12 \mathrm{mM}$ & $5.7 \mu \mathrm{M}$ & $1.9 \mathrm{mM}$ & $4 \mathrm{mM}$ & $\sim 12 \mathrm{mM}$ & $\sim 18 \mathrm{mM}$ & $\sim 123 \mathrm{mM}$ \\
Serum (out) & $4 \mathrm{mM}$ & $145 \mathrm{mM}$ & $1.8 \mathrm{mM}$ & $0.8 \mathrm{mM}$ & $116 \mathrm{mM}$ & $\sim 29 \mathrm{mM}$ & $\sim 1.2 \mathrm{mM}$ & $\sim 8 \mathrm{mM}$ \\
In/Out & 35 & 0.08 & 0.003 & 2.4 & 0.034 & 0.414 & 15 & 15.3 \\
In (a/b) & 12 & $\mathrm{NA}$ & 0.003 & $\mathrm{NA}$ & 0.333 & $\mathrm{NA}$ & $\mathrm{NA}$ & $\mathrm{NA}$ \\
Out (b/a) & $\mathrm{NA}$ & 36 & $\mathrm{NA}$ & 0.44 & $\mathrm{NA}$ & 0.25 & $\mathrm{NA}$ & $\mathrm{NA}$ \\
\hline
\end{tabular}

(NA: not applicable or not available); (*a/b or b/a values are taken for the respective columns of monovalent cations, divalent cations and monovalent anions only); ${ }^{\#}$ (extrapolated from the principle of phase of electroneutrality) Consensus data chiefly compiled from cited textbooks and other sources (Milo \& Phillips, 2015; Reza et al., 2019).

Table 2: Fundamental physical attributes of the four cations explored herein.

\begin{tabular}{|c|c|c|c|c|c|}
\hline S. No. & Criteria & $K(+)$ & $\mathrm{Na}(+)$ & $\mathrm{Ca}(++)$ & $\mathrm{Mg}(++)$ \\
\hline 1 & Abundance & $2.09 \%$ & $2.36 \%$ & $4.15 \%$ & $2.33 \%$ \\
\hline 2 & Atomic mass & $39 \mathrm{~g}$ & $23 \mathrm{~g}$ & $40 \mathrm{~g}$ & $24.3 \mathrm{~g}$ \\
\hline 3 & Solubility $(\mathrm{C} \Gamma)$ & $4.6 \mathrm{M}$ & $6.1 \mathrm{M}$ & $6.7 \mathrm{M}$ & $5.7 \mathrm{M}$ \\
\hline 4 & Ionic radius & $152-138 \mathrm{pm}$ & $116-102 \mathrm{pm}$ & $114-100 \mathrm{pm}$ & $86-72 \mathrm{pm}$ \\
\hline 5 & Charge density & 0.59 & 1.06 & 2.24 & 4.3 \\
\hline 6 & $J D V B C$ & -0.007 & 0.086 & 0.285 & 0.385 \\
\hline 7 & $A D H N$ & 0 & 0.22 & 2.1 & 5.9 \\
\hline 8 & $\Delta_{f} G_{a q}^{\circ}$ & $129 \mathrm{~kJ} / \mathrm{mol}$ & $151 \mathrm{~kJ} / \mathrm{mol}$ & $271 \mathrm{~kJ} / \mathrm{mol}$ & $370 \mathrm{~kJ} / \mathrm{mol}$ \\
\hline 9 & GSE & $-352 \mathrm{~kJ} / \mathrm{mol}$ & $-424 \mathrm{~kJ} / \mathrm{mol}$ & $-1608 \mathrm{~kJ} / \mathrm{mol}$ & $-1931 \mathrm{~kJ} / \mathrm{mol}$ \\
\hline
\end{tabular}

Charge density is relative to water taken as 1; JDVBC: Jones-Dole viscosity B coefficient; ADHN- apparent dynamic hydration number is a relative additive scale with $\mathrm{K}^{+}$taken as $0 ; \boldsymbol{\Delta}_{f} \boldsymbol{G}_{a q}^{\circ}$ : Standard Gibbs' free energy of formation in water; GSE: Gibbs solvation energy. The values are taken from CRC Handbook and recent publications (Collins, 2012,2019; Bazhin, 2020).

As water is found both in and out of cells, 'water-affinity' alone cannot serve as the deterministic criterion for cation or anion differentials. The phospholipid bilayer is anionic and somewhat asymmetrical in essence (on one side is open water and the other side is closed water). Therefore, its ability to repel anions and permit some cations cannot be ruled out. However, it cannot 
determine why the concentration profile is $\mathrm{K}>\mathrm{Na}$ in the inside whereas $\mathrm{Na}>\mathrm{K}$ it is outside. Simple analyses in Table 1 show that there is no tangible rationale for the observed stoichiometry of various anions or cations and their absolute or relative concentrations (and this aspect is corroborated by the data on ionic differentials in several other cellular systems). This fact downplays the deterministic roles of stoichiometric ion pumps. The association-induction hypothesis $(\mathrm{AIH})$ postulates that hydration shell of ions is more important in determining the abundance of ions. Quite like the Hofmeister series based prediction, this criterion gets the $\mathrm{K}>\mathrm{Na}$ order right but it is misplaced for the divalent ions. It can be envisaged that the relative abundance/solubility of the ions could determine their bioavailability, which, in turn, could be reflected in cellular composition. Further, ionic mass and charge would determine affinity/recognition and work done in moving ions across membranes. Such parameters were not found to directly/tangibly correlate to the physiological distribution of the cations, when considering the full spectrum of $\mathrm{K}-\mathrm{Na}-\mathrm{Ca}-\mathrm{Mg}$. Ionic dimensions could determine filtration/mobility across membranes/channels and could also affect the hydration shell sizes. Therefore, it is a very important criterion for both the classical membrane theorists (Voet \& Voet, 2011) and AIH (as seen in Gilbert Ling's works at www.gilbertling.org). This is the reason why data are presented in the order of decreasing ionic radius in Tables $1 \& 2$. Yet again, it is difficult for us to envisage that membrane pores could kinetically/viably enable a selective differentiation of di- or mono- valent ions of dimensions ranging $\sim 1.7 \AA\left(\mathrm{Mg}^{2+}\right)$ to $\sim 2.3 \AA\left(\mathrm{Ca}^{2+}\right.$ or $\left.\mathrm{Na}^{+}\right)$to $\sim 3.0 \AA\left(\mathrm{K}^{+}\right)$. That is: while the smaller species can be easily selected, the larger species would invariably/statistically bring along the smaller one, if size/charge were the deterministic criteria. This predicament would necessitate directional pumps/channels for each of the species, and such processes would not be viable. The later rows of Table 2 show that the differences in charge density, viscosity-hydration features and thermodynamic properties are significant for the four ions. Ionic radius is inversely correlated to Gibbs free energy of formation or $\boldsymbol{\Delta}_{\boldsymbol{f}} \boldsymbol{G}_{\boldsymbol{a} \boldsymbol{q}}^{\circ}$ (i.e. as ionic radius decreases, $\boldsymbol{\Delta}_{\boldsymbol{f}} \boldsymbol{G}_{\boldsymbol{a} \boldsymbol{q}}^{\circ}$ increases) and directly correlated to Gibbs solvation energy or GSE (i.e. as ionic radius decreases, GSE also decreases). The hydration radius argument (as espoused by $\mathrm{AIH}$ ) would predict the cellular availability along the order $\mathrm{K}>\mathrm{Na}>\mathrm{Ca}>\mathrm{Mg}$ over the spectrum. That is: $\mathrm{K}>\mathrm{Na}$ for monovalent ions and $\mathrm{Ca}>\mathrm{Mg}$ for divalent 
ions. The actual physiological order is $\mathrm{K}>\mathrm{Na}>\mathrm{Mg}>\mathrm{Ca}$. Therefore, at the surface, a clearly deterministic rationale for ion distribution appears to be lacking.

The ionic differential is lost gradually upon cell death. The signature functional attribute of cellular life is its respiratory activity, and this in turn, is fundamentally based in murburn principles (or molecule-unbound ion-radical equilibriums). Therefore, it is forthright to postulate that cellular ionic composition would be dictated by the overall process of murburn redox metabolism and its catalysts-intermediates-products. Therefore, it is natural to deduce that the cations 'preferred or adsorbed' by proteins, the stable and relatively non-changing salient components of life, would surely influence cationic distribution. This deduction is supported by Table 1, which shows that protein concentrations are significantly different in erythrocytes and serum/plasma. Further, it is also natural to infer that the processes and intermediates/products of respiration would have high influence on the cation distribution in cells. Therefore, the ion-pair solubility of the four cations with four anions of respiratory relevance (for which we could easily access data from literature: carbonate, acetate, bicarbonate and phosphate) were probed from the solubility table. Table 3 presents the summary of this data, which shows that two anions gave a solubility profile of the same relative order as found in RBC for all the four cations, and two more anions gave good correlations with at least three of the cations. Unlike the solubility reference data for chloride, these anions show a high degree of selectivity/variance for the four cations. However, chloride has a higher solubility with sodium and calcium when compared to its solubility with potassium and magnesium respectively; therefore, the former cations predominate in the serum!

Table 3: Absolute solubility and relative solubility ratios of some salts in water at $20^{\circ} \mathrm{C}$.

\begin{tabular}{cccccc}
\hline S. No. & Anion & $\mathbf{K ~ ( + )}$ & $\mathbf{N a ~ ( + ) ~}$ & $\mathbf{C a}(++)$ & $\mathbf{M g}(++)$ \\
\hline 1 & Carbonate & $8.04 \mathrm{M}$ & $2.02 \mathrm{M}$ & $70 \mu \mathrm{M}$ & $4.6 \mathrm{mM}$ \\
& (Ratio) & $\mathbf{1 . 7 \times 1 0 ^ { 3 }}$ & $\mathbf{4 . 4 \times 1 0 ^ { 2 }}$ & $\mathbf{1 . 5 \times 1 0 ^ { - 1 }}$ & $\mathbf{1}$ \\
2 & Acetate & $26 \mathrm{M}$ & $5.7 \mathrm{M}$ & $2.2 \mathrm{M}$ & $3.75 \mathrm{M}$ \\
& (Ratio) & $\mathbf{6 . 9}$ & $\mathbf{1 . 5}$ & $\mathbf{0 . 6}$ & $\mathbf{1}$ \\
3 & Bicarbonate & $2.24 \mathrm{M}$ & $1.14 \mathrm{M}$ & $1.02 \mathrm{M}$ & $4.2 \mathrm{mM}$ \\
& (Ratio) & $\mathbf{5 . 3 \times 1 0 ^ { 2 }}$ & $\mathbf{2 . 7 \times 1 0 ^ { 2 }}$ & $2.4 \times 10^{2}$ & $\mathbf{1}$ \\
4 & Phosphate & $4.35 \mathrm{M}$ & $0.74 \mathrm{M}$ & $64.5 \mu \mathrm{M}$ & $1 \mu \mathrm{M}$ \\
& (Ratio) & $\mathbf{6 . 7 \times 1 0 ^ { 4 }}$ & $\mathbf{1 . 1 \times 1 0 ^ { 4 }}$ & $\mathbf{1}$ & $1.6 \times 10^{-2}$ \\
\hline & & & & &
\end{tabular}




\begin{tabular}{cccccc} 
Ref. & Chloride & $4.6 \mathrm{M}$ & $6.1 \mathrm{M}$ & $6.7 \mathrm{M}$ & $5.7 \mathrm{M}$ \\
& (Ratio) & 0.84 & 1.07 & 1.2 & 1 \\
\hline
\end{tabular}

(Solubility table available in Wikipedia, as extracted from CRC Handbook of Chemistry \& Physics)

Therefore, the combined solubility of the anion+cation pair must contribute to the physiological outcomes. Carbonate/bicarbonate and acetate are directly the output of carbon metabolism (aerobic respiration) and phosphate is the anion involved in bioenergetic turnovers. Particularly, it can be seen that phosphate is very selective to potassium, as opposed to calcium; thereby explaining the oddly high selectivity discussed for $\mathrm{K}>\mathrm{Na} \gg>\mathrm{Ca}$ in Table 1. Significant concentrations of carbonate-bicarbonate and phosphate ions are found within cells, in the ranges of $10^{1} \mathrm{mM}$. In fact, further search showed that organic phosphates (e.g. ATP/UDP, hexose phosphate, pentose phosphate, etc.) and organic acids (like glutamate, aspartate, citrate, malate, succinate, acetate, etc.) compose a whopping $\sim 68 \%$ of the anionic charge. With proteins making up $\sim 18 \%$ with the carboxylates of aspartate/glutamate residues, the vast majority of cellular anionic charges $(\sim 86 \%)$ are thus accounted (Bennet et al., 2009; Anderson, 2013; Milo \& Philips, 2015) in E. coli. So, it is forthright to infer that the skewed cationic distribution primarily results as a direct outcome of the powering murburn equilibriums/fluxes (Manoj, 2018; Manoj, 2020; Manoj \& Bazhin, 2021) within metabolism/physiology. The lower contribution of protein anionic component $(<20 \%)$ cannot explain the preponderantly high $\mathrm{K}^{+}$or low $\mathrm{Ca}^{+}$ concentrations in cells, as adsorption can only be stoichiometric. That is, even if all of the anionic charges of proteins in a cell selectively bound only $\mathrm{K}^{+}$, if would still amount to only $<30$ $\mathrm{mM} \mathrm{K}^{+}$excess over another cation like $\mathrm{Na}^{+}$. This premise cannot explain the fact that $\mathrm{K}^{+}$exceeds $\mathrm{Na}^{+}$by $127 \mathrm{mM}$ in RBCs (Table 1).

The total concentration of major cations $\left(\mathrm{K}^{+}\right.$and $\left.\mathrm{Na}^{+}\right)$turns out to be $\sim 150 \mathrm{mM}$ (both in and out of RBC) and the minor cations $\left(\mathrm{Ca}^{2+}\right.$ and $\left.\mathrm{Mg}^{2+}\right)$ add up to $\sim 2 \%$ of the above value (Table 1). At equilibrium, the law of electro-neutrality holds; dictating that concentration of the total anionic charges should equal the cationic charges in each phase. A major difference between erythroplasm and serum is the concentration of proteins, the biggest 'life protagonist' in cytoplasm. It is long known that Hofmeister series (Okur et al., 2017) indicates that the experimentally observed cation binding/adsorption of most cytoplasmic proteins is approximated 
in the order $\mathrm{K}^{+}>\mathrm{Na}^{+}>\mathrm{Mg}^{++}>\mathrm{Ca}^{++}$. Therefore, binding affinities of bulk-phase proteins, permittivity of membrane, selectivity afforded by the membrane-embedded proteins, and solubility of the respective cation with the anions involved in metabolic turnovers (which result out of proteins' catalytic activities!) can come together as an integral function to achieve the physiological distribution of ions in cells. This is a simple and parsimonious deduction, and it is also supported by the consideration that highly sophisticated membrane-embedded ion-pumps would not be needed for the evolution of life in the primordial stages. Therefore, our explanations propose that while binding-based selectivity explanation may be relevant (Korolev, 2021), it cannot be adequate. Further, attainment of the physiological distribution of ions within the bulk-liquid phase would not require any intelligent control via the regulation of membraneproteins' concentrations/functions or through exorbitant expenditure of ATP. In this regard, we present a contextually relevant analogy. The number or type of people or living beings that reside in a locale (say, a county or country) is decided by screening at the borders (membrane theory components), by the active discretion of resident citizens (protein adsorption by AIH theory components) and most importantly, by the inhospitable ambiance like absence of unoccupied houses (ion-pair solubilization concept of murburn model). In addition, murburn concept also enlists the interconnectivity of the overall process- why some borders can't be policed, why some residents do not like drifters, etc. as can be gathered below.

For salvation of any ion, the solvent-lattice must be broken first to introduce a cavity, into which ions can be placed. This process is both enthalpically and entropically disfavored. For explaining the ionic distribution 'in and out' of the physiological cell, the primary reason for migration and solvation of 'anion+cation' couplet is aided by discretized murburn reaction equilibriums leading to a distribution of respiratory molecules. Also, solubilized proteins serving as adsorbents and semipermeable membranes with their embedded channels aiding facilitated/selective entry/exit of ions play crucial roles in the outcome. Evidence to our deduction is provided by the earlier pioneering works of several researchers (Spector, 1953; Amoore, 1959; Brierly et al., 1970) on the study of concentrations of various metabolites and factors that induce swelling in organelles like mitochondria. Earlier experiments demonstrating the ability of mitochondria to concentrate carboxylates/phosphates and the correlation of the permeability of anions to cause swelling is 
crucial to understand the solubilization of ions in cellular milieu. Myriads of such findings were overlooked because of explanations classified into the two groups membrane pump or ionadsorption schools of theories. In this regard, it is important to cite that several researchers (like Kim D. Collins) have championed the concept of water affinities of ions and ion-pairing affects/effects for explaining the stability and solubility of proteins (van der Vegt et al., 2016; Collins, 2012, 2019). The murburn proposal is substantiated by the fact that electron transfer phenomena are associated with ion-pairing at water-interfaces (van der Vegt et al., 2016; Roy et al., 2017). We explore this aspect with the thermodynamic rationale below.

Murburn thermodynamic model for ionic differentiation at membrane interface: A cell is structurally and functionally characterized by its proteins, which bear predominantly negative/anionic charges. (We shall not delve into the negative charges on phospholipids and DNA now, as the discussion focuses on the main agents only.) These proteins' formation, and the maintenance of their structure and function critically depend on the ions inside. So, it is not possible to prioritize the proteins over the ions (or the ions over the proteins), as it would be a classical 'chicken-egg conundrum'. However, if we start from the assumption that a cell contains fully functional proteins and distribution of the necessary ions, then we can theorize and study the steady-state traffic/flux of ions at the membrane interface. We have already shown via Table 2 that the reactivity of the ions varies significantly, as exemplified in the thermodynamic parameters. Based on this fact, the overall stochastic and bimolecular murburn scheme for Na-K ion-differentiation is captured in Figure 2. Further, the following electron-transfer processes in the textbox (which may be catalyzed by ATPases) may be relevant to account for the overall outcomes-

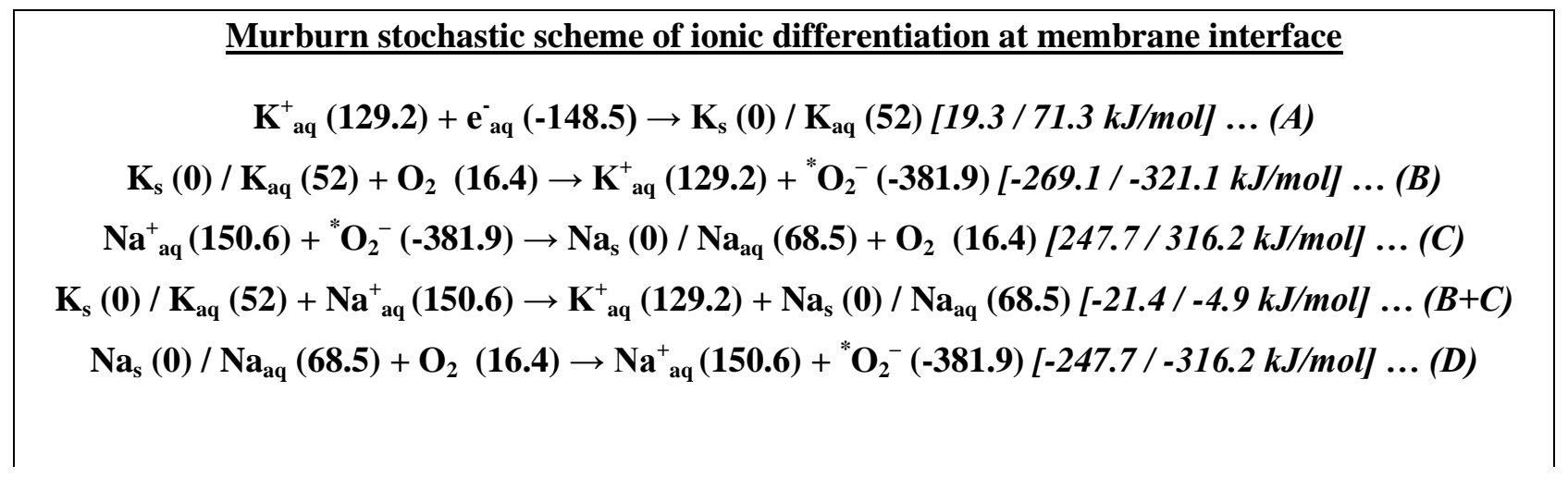


Ions such as $\mathrm{Mg}^{2+}$ serve as a catalyst in the scheme, between $\mathrm{K}^{+}$and $\mathrm{Na}^{+}$:

$$
\mathrm{Mg}^{2+}{ }_{\text {aq }}(370.2)+\mathrm{e}_{\text {aq }}^{-}(-148.5) \rightarrow \mathrm{Mg}^{+}{ }_{\text {aq }}(150)[-71.7 \mathrm{~kJ} / \mathrm{mol}] \ldots(E)
$$

$\mathrm{Mg}^{+}{ }_{\mathrm{aq}}(150)+\mathrm{K}_{\mathrm{aq}}^{+}(129.2) \rightarrow \mathrm{Mg}^{2+}{ }_{\mathrm{aq}}(370.2)+\mathrm{K}_{\mathrm{s}}(0) / \mathrm{K}_{\mathrm{aq}}(52)[91 / 143 \mathrm{~kJ} / \mathrm{mol}] \ldots$ (F)

$\mathrm{Mg}^{+}{ }_{\mathrm{aq}}(150)+\mathrm{Na}^{+}{ }_{\mathrm{aq}}(150.6) \rightarrow \mathrm{Mg}^{2+}{ }_{\mathrm{aq}}(370.2)+\mathrm{Na}_{\mathrm{s}}(0) / \mathrm{Na}_{\mathrm{aq}}(68.5)[69.6 / 138.1 \mathrm{~kJ} / \mathrm{mol}] \ldots(\mathrm{G})$

$\mathrm{K}_{\mathrm{s}}(0) / \mathrm{K}_{\mathrm{aq}}(52)+\mathrm{O}_{2}(16.4) \rightarrow \mathrm{K}^{+}{ }_{\mathrm{aq}}(129.2)+{ }^{*} \mathrm{O}_{2}^{-}(-381.9)[-269.1 /-321.1 \mathrm{~kJ} / \mathrm{mol}] \ldots(\mathrm{H})$

$\mathrm{Na}_{\mathrm{s}}(0) / \mathrm{Na}_{\mathrm{aq}}(68.5)+\mathrm{O}_{2}(16.4) \rightarrow \mathrm{Na}^{+}{ }_{\mathrm{aq}}(150.6)+{ }^{*} \mathrm{O}_{2}^{-}(-381.9)[-247.7 /-316.2 \mathrm{~kJ} / \mathrm{mol}] \ldots$ (I)

The nett equation (with a highly favorable $\mathrm{K}_{\mathrm{eq}} \sim 6.1 \times 10^{43}$ ) is:

$\mathrm{O}_{2}(16.4)+\mathrm{e}_{\mathrm{aq}}^{-}(-148.5) \rightarrow{ }^{*} \mathrm{O}_{2}^{-}(-381.9)[-249.8 \mathrm{~kJ} / \mathrm{mol}] \ldots(J=A+B+C+D=E+F+H=E+G+I)$

At the interface, since there exists a higher concentration of the superoxide radical and respiratory metabolites on the cytoplasm side (due to murburn bioenergetic activities associated with life), the association of potassium ion is favored. Whereas since chloride is the pairing ion on the extracellular region, the e-transfer equilibriums ensure a displacement of sodium ions towards that direction. Summating, this occurs because of the following fundamental difference in the thermodynamic dispostion of the two alkali metal ions: $\mathrm{K}_{\mathrm{s}} \rightarrow \mathrm{K}^{+}{ }_{\mathrm{aq}}+\mathrm{e}_{\mathrm{aq}}^{-}(-19.3 \mathrm{~kJ} / \mathrm{mol})$ and $\mathrm{Na}^{+}{ }_{\mathrm{aq}}+\mathrm{e}_{\mathrm{aq}}^{-} \rightarrow \mathrm{Na}_{\mathrm{s}}(-2.1 \mathrm{~kJ} / \mathrm{mol})$. This premise enables the $\left(\mathrm{O}_{2}-\mathrm{ROS}\right.$ catalyzed $)$ reaction: $\mathrm{K}_{\mathrm{s}}$ $+\mathrm{Na}^{+}{ }_{\mathrm{aq}} \rightarrow \mathrm{K}_{\text {aq }}^{+}+\mathrm{Na}_{\mathrm{s}}\left(-21.4 \mathrm{~kJ} / \mathrm{mol}, \mathrm{K}_{\mathrm{eq}}=5.6 \times 10^{3}\right)$. Since $\mathrm{Na}_{\mathrm{s}}$ reaction with oxygen is facile $\left(\mathrm{Na}_{\mathrm{s}}+\mathrm{O}_{2} \rightarrow \mathrm{Na}^{+}{ }_{\mathrm{aq}}+{ }^{*} \mathrm{O}_{2}{ }^{-} ;-248 \mathrm{~kJ} / \mathrm{mol}\right), \mathrm{Na}^{+}$ion is predominantly paired and solvated with chloride on the outside whereas $\mathrm{K}^{+}$ion is paired with superoxide in the membrane and solvated with phosphate on the inside. In the murburn purview, this is the mechanism of how proteins like Na-K ATPase could help in the differentiation of the two ions at the interface and it can be seen that this explanation is quite distinct from deterministic/stoichiometric ion-pumping. This mechanism explains why the ionic differential drops when the respiratory consumption of oxygen stops. WHO prescribes the daily requirement of $\mathrm{Na}$ and $\mathrm{K}$ at $\sim 2.0 \mathrm{~g}(\sim 0.09$ moles) and $\sim 3.5 \mathrm{~g}$ (0.09 moles); whereas $\mathrm{Cl}$ and $\mathrm{P}$ requirements are $\sim 2.3 \mathrm{~g}$ (0.065 moles) and $0.7 \mathrm{~g}(0.023$ moles) respectively. As sulfur and nitrogen centered anionic species are minimal in physiology, the above reality dictates that carbon-centered anionic species like inorganic (bi)carbonate and organic carboxylates are responsible for the missing account in outward fluxes, and the major bulk of phosphates are retained by cells. This argument is also in agreement with the phosphate 
anion bearing phospholipid of the cell membranes, which could retain phosphates within the cells by the electrostatic argument of 'like repels like' (Figure 2).
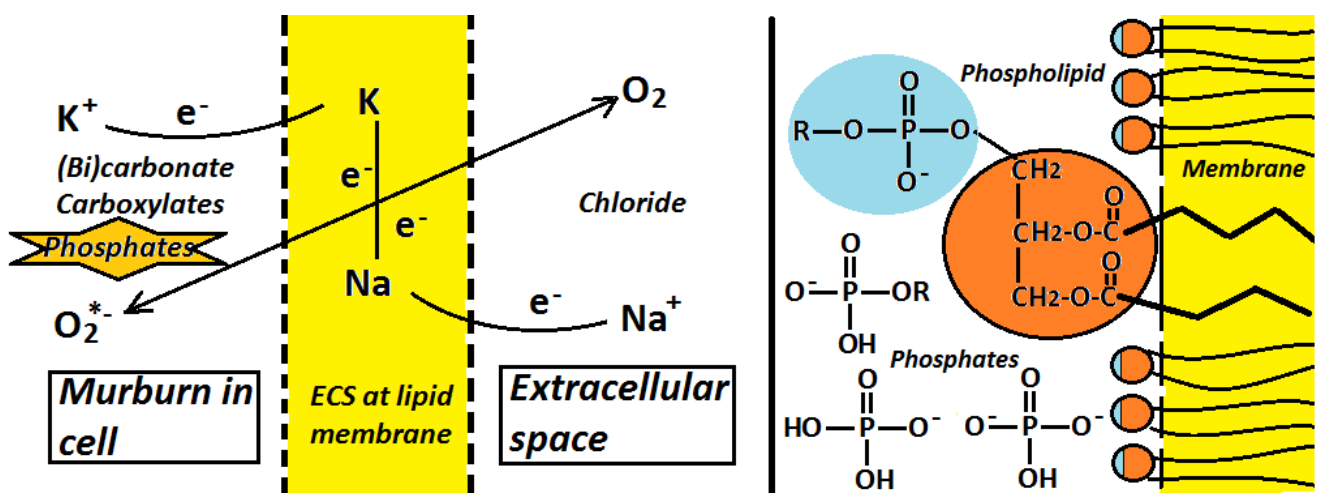

Figure 2: The murburn perspective of ion-differentiation at the membrane interface (murzone) results due to one-electron equilibriums and the availability of select ions like phosphate within the cells. The schematic model of the head group of a generic phospholipid is shown on the right, along with the molecular structure of physiologically preponderant inorganic phosphates, and representation of organic phosphate that are found at high concentrations within cells.

Murburn explanation for TMP: Since we have postulated that ionic homeostasis is based in murburn concept, it is natural to theorize that the origin of TMP (whether resting potential RP, graded potential GP, or action potential AP) in cells could be involved with murburn principles, as was the case in mitochondria (Manoj \& Bazhin, 2021). We approach the issue of trans-phase potentials in the biological systems from a new perspective and think beyond the merely ionic origin (which we do not deny; and consider as an important contributor to TMP!). We also look for other/faster components that could contribute to TMP temporal fluctuations in cellular systems. While the membrane theory treatments (like GHK equation and Hodgkin-Huxley model) and $\mathrm{AIH}$ maintain that macroscopic electroneutrality holds within a given phase, murburn concept's key principle of 'effective charge separation' (ECS) goes beyond this stricture. It proposes that electrons can be exchanged across phases, and this could contribute to potential differences and their reversals. To cite an example, in dry conditions, static electricity is easily generated at interfaces; rubbing a balloon renders it negatively charged. This potential difference across phases results due to the transfer of electrons (and not ions!) and clearly violates the electroneutrality within the phase. (Please see that murburn concept does not violate the law of conservation of charges!) Gerald Pollack's (2001) works have demonstrated that 
closed micro-aqueous regimes could behave significantly differently from bulk water milieu. We have argued that free protons and hydroxide ions are very limited in micro-dimensioned biological realms. In such scenarios, the potential generated due to ECS may not dissipate that easily like normal milieu. Further, the properties of cellular/organellar medium behaves more like an intermediate of sol-gel and liquid; and it would also be governed by small amounts of interfacial adsorption of ions (by membrane or bulk phase components) and electron transfer chemistry occurring within interfaces/milieu. The low dielectric properties of the lipid membrane, ordering of water-chaotropes at one side of the interface and water-kosmotropes on the other side, in combination with the effective charge separation enabled around its ambiance must be deemed important. These overlooked facets could help to better understand the generation, sustenance and reversal of potentials and conduction of electrical impulses in excitable cells. With this perspective, the new theorization aims to amalgamate the known facts $a b$ initio, into a holistic perspective so that the phenomena could be comprehensively explained. Figure 3 depicts a simple molecular level explanation for the original of extra-ionic TMP. An example of a simple interface embedded heme-enzyme catalyzed reaction is shown.

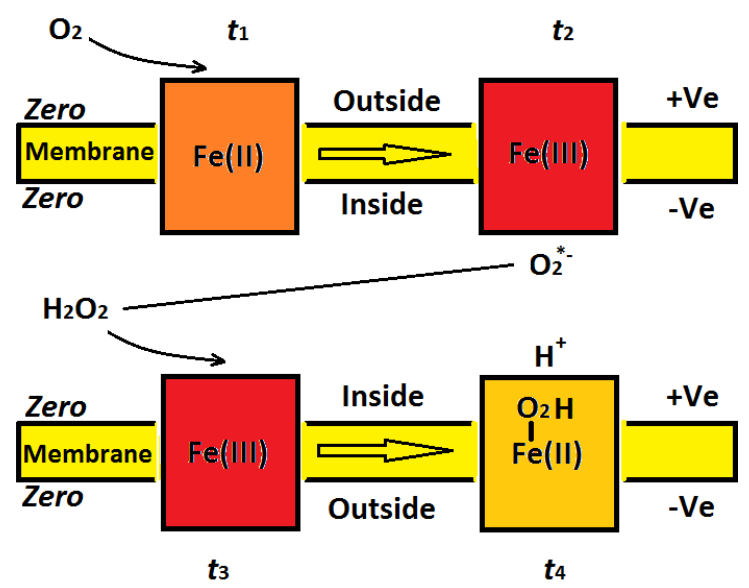

Figure 3: Trans-membrane potential can be affected by interfacial electron transfers and adsorption processes. (For details, please refer manuscript text.)

At $\mathrm{t}_{1}$ (starting from zero potential), an oxygen molecule interacts with a ferrous species generating a ferric center and superoxide inside $t_{2}$, giving a negative potential difference (in versus out). With more superoxide inside, a dismutation reaction at $t_{3}$ could enable the formation of peroxide (taking in protons from the outside, owing to the facile neutralization of generated potential difference). This process would lead to a lowering of the potential difference. Now, the 
DROS species could bind at the immobilized iron-center, liberating a proton inside, thereby resulting in a positive potential (in versus out) at time $t_{4}$. Thereby, with the presence of a simple metal-center containing membrane-embedded redox ezyme, TMP could vary in time. This process may be associated with influx/adsorption of ions/water (or both or neither). It can be imagined that this process could also occur spontaneously in non-living systems, as oxygensuperoxide-peroxide-water equilibrium is a ubiquitous phenomenon and contrary to common perception, formation of superoxide radical is facile in aqueous milieu (Stoin et al., 2013). The murburn proposal for TMP is strongly supported by the fact that DROS and been positively correlated to membrane potential in mitochondrial (Nicholls, 2005) and cell (Scott \& Rabito, 1988) membranes. It can be envisaged that the above process can also give rise to threshold physiology differentiation of graded and action potentials. Given a particular geometry and the number of channels/proteins present, the triggering of a channel may result only if an adequate amount of a product of the murburn equilibrium is formed. Figure 4 projects the molecular modality for the propagation of an action potential impulse along the nerve axon, which is an extension of the originally floated proposal in our recent paper on photoreception at retina (Manoj \& Jacob, 2020).

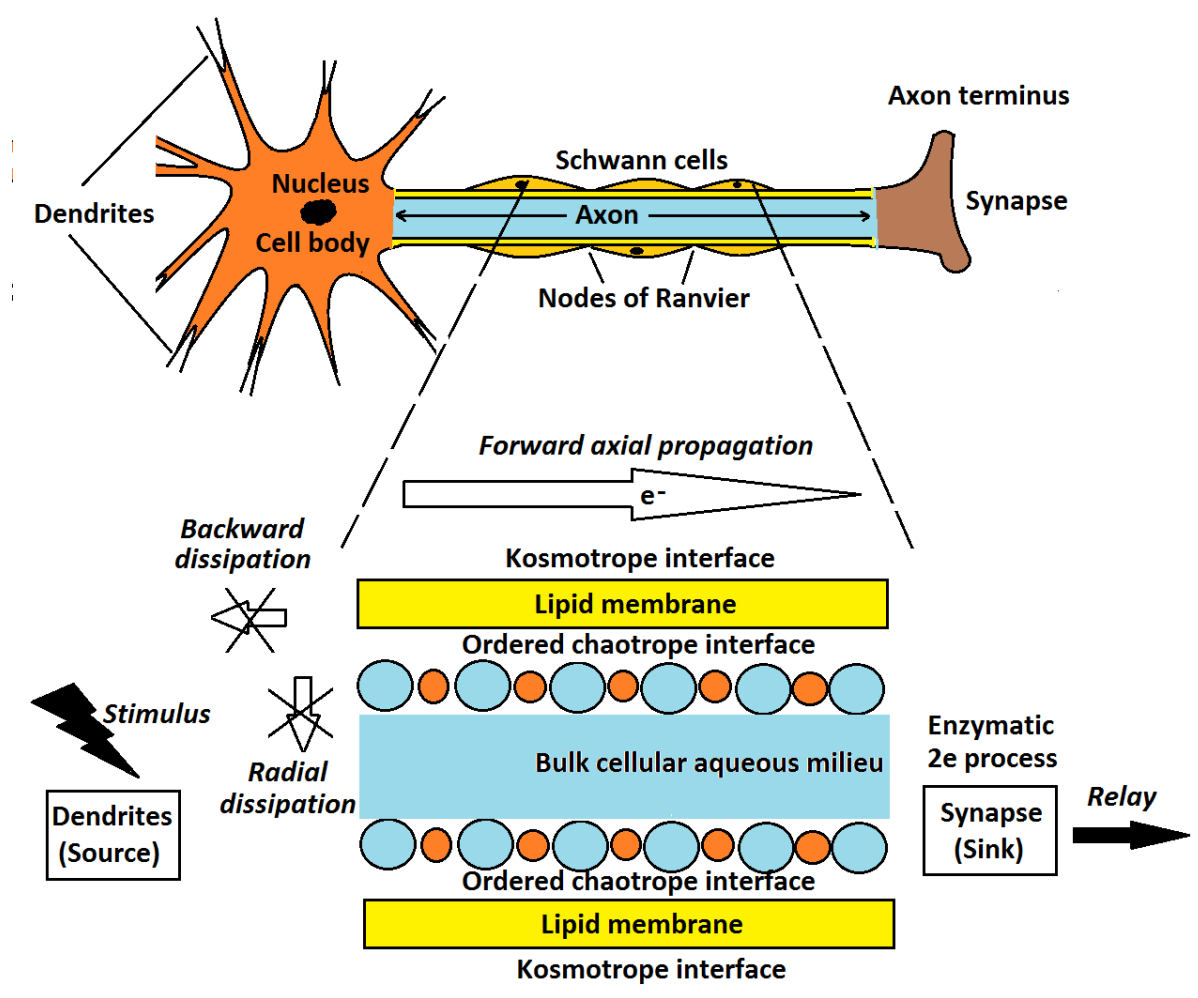


Figure 4: A pictorial rendition of the phenomenology of signal relay (conduction of action potential impulse) across neurons, on a $2 D$ plane. (Please refer manuscript text for details.)

We have theorized that light can be trapped by retinoid containing proteins like rhodopsin. Also, touch/pressure and various other radio-mechano-chemical stimuli can directly perturb membrane-cytosol one-electron equilibriums. This would serve as direct electrical stimulus, which could be relayed via an electrochemical impulse along the ordered membrane interface of neurons, which is observable as action potential. The molecular basis for depolarization would be the event of consumption or release of superoxide from the inside. This could lead to the disruption of the chaotrope/kosmotrope ordered lipid interface. This perturbation can translate into an electron transfer cascade along the axon. The structure of the interface retains the relay along the same, and does not permit radial or backward dissipation. This arrangement would agree with why myelinated neurons relay faster (as the degree of freedom is restricted in this system) and why there is no energy loss along the conducting length. The e-transfer reactions shown in the textbox show that the efficiency is quite high. In the new molecular mechanism, diverse types of stimuli could be transduced via various molecule-ion-ROS equilibriums and threshold physiologies could also be explained. The new model for TMP fluctuations proposed herein could explain the action potential like trace in proteinoids (Vaughn et al., 1987) and gels functionally along the Lillie's Fe-wire model (Lillie, 1918).

Experimental ratification for the murburn explanation for cation distribution \& TMP variation: (i) The preliminary aspects of our predictions for cation distribution can be easily tested as follows: With a bi-compartmental system (separated by a semi-permeable membrane) housing a mixture of chloride salts of $\mathrm{K} / \mathrm{Na} / \mathrm{Mg} / \mathrm{Ca}$, various organic phosphates, carbonates, acetates, etc. could be introduced into one of the compartment. Preferential migration of ions or alteration of concentration of ions could be achieved by the introduction of one-electron transfer activities in the same or other compartment. (ii) The highly transient redox cycles of $\mathrm{Mg}$ and $\mathrm{Na}$ could be traced through spectroscopy techniques. (iii) The electronic source of TMP (particularly with respect to AP) can be demonstrated by taking a simple experimental setup and adding a redox enzyme like peroxidase to the inside compartment (with peroxide + electron source like aromatic amines; presented both inside and outside). The murburn perspective predicts a small and detectable negative potential development at the onset of enzyme addition, owing to the 
production of superoxide. We have partially demonstrated the theoretical feasibility of such an outcome in a recent communication (Tamagawa et al., 2021). (iv) In oxic environments, attempt can be made to trace action potential type phenomena in non-neuron type cells and artificial systems with the provision of DROS cues and the result in the earlier experiment can be contrasted with the experiment conducted in the absence of oxygen. (v) The murburn model projects the observation of concentration dependent effects upon the inclusion/injection of polar and hydrophobic DROS scavengers; both in large neurons and in artificial model systems.

\section{Summation}

Over the last five years, the relevance of murburn concept has been demonstrated in xenobiotic/bioenergetic redox metabolism and physiology. In continuance with our pursuits along this direction, we have proposed a thermodynamically grounded molecular mechanism for the phenomenon of ion-selectivity/homeostasis and TMP. We also that the electrophysiology of TMP (GP and AP) and homeostatic responses in cells are intricately connected, and involves oxygen-centric equilibriums involving various protein molecules, ions and transiently generated one-electron active species. While we do not negate the ionic contribution to TMP, we project that the phenomena associated with electron-transfers could provide a compelling new angle to explain the thermodynamics of preferential ion solubilization in cells and signal transductionpropagation in the excitable neurons. We have also provided modalities to further explore our new proposals.

Declarations: The work was powered by Satyamjayatu: The Science \& Ethics Foundation. The authors have no conflict of interests to declare.

\section{References}

1. Alberts, B., Johnson, A., Lewis, J., Raff, M., Roberts, K., Walter, P. Molecular Biology of the Cell $4^{\text {th }}$ edn. Garland Science (2002).

2. Amoore, J. E. The permeability of isolated rat-liver mitochondria at 0 degree to the metabolites pyruvate, succinate, citrate, phosphate, adenosine 5'-phosphate and adenosine triphosphate. Biochem. J. $70: 718$ (1959).

3. Andersen, O. 'Cellular electrolyte metabolism' in Encyclopedia of Metalloproteins, Springer, pp. 580-587 (2013). 
4. Andrew, D. et al. The intriguing enhancement of chloroperoxidase mediated one-electron oxidations by azide, a known active-site ligand. Biochem. Biophys. Res. Commun. 415, 646-649 (2012).

5. Bazhin, N. M. Standard values of the thermodynamic functions of the formation of ions in an aqueous solution and their change during solvation. J. Phys. Chem. A.124, 11051-11060 (2020).

6. Bennett, B., Kimball, E., Gao, M. et al. Absolute metabolite concentrations and implied enzyme active site occupancy in Escherichia coli. Nat Chem Biol 5, 593-599 (2009)

7. Berg, J. M., Tymoczko, J. L., Stryer, L. Biochemistry $5^{\text {th }}$ edn. W H Freeman (2002).

8. Brierly, G. P. et al. Ion transport by heart mitochondria: XX. Factors affecting passive osmotic swelling of isolated mitochondria. J. Biol. Chem. 245, 5404-5411 (1970).

9. Collins, K. D. Why continuum electrostatics theories cannot explain biological structure, polyelectrolytes or ionic strength effects in ion-protein interactions. Biophys Chem. 167:43-59 (2012).

10. Collins, K. D. The behavior of ions in water is controlled by their water affinity. Quart. Rev. Biophys. 52, e11, 1-19 (2019).

11. Gideon, D. A., et al. Are plastocyanin and ferredoxin specific electron carriers or generic redox capacitors? Classical and murburn perspectives on two photosynthetic proteins. J. Biomol. Struct. Dyn. (2020). doi: 10.1080/07391102.2020.1835715.

12. Gideon, D. A., et al. Mechanism of electron transfers mediated by cytochromes c and b5 in mitochondria and endoplasmic reticulum: Classical and murburn perspectives. J. Biomol. Struct. Dyn. (2021). doi: 10.1080/07391102.2021.1925154.

13. Korolev, N. How potassium came to be the dominant biological cation: of metabolism, chemiosmosis, and cation selectivity since the beginnings of life. Bioessays 43(1):e2000108 (2021).

14. Lillie, R. S. Transmission of activation in passive metals as a model of protoplasmic or nervous type of transmission. Science. 48:51-60 (1918).

15. Manoj, K. M. \& Hager, L. P. Chloroperoxidase, a Janus enzyme. Biochemistry 47, 2997-3003 (2008).

16. Manoj, K. M. \& Jacob, V. D. The murburn precepts for photoreception. (In Press) Biomed. Rev. 31 (2020). doi: 10.31219/osf.io/gmd5t

17. Manoj, K. M. \& Manekkathodi, A. Light's interaction with pigments in chloroplasts: The murburn perspective. J. Photochem. Photobiol. 5, 100015 (2021).

18. Manoj, K. M. Chlorinations catalyzed by chloroperoxidase occur via diffusible intermediate(s) and the reaction components play multiple roles in the overall process. Biochim. Biophys. Acta 1764, 1325-1339 (2006).

19. Manoj, K. M. et al. Acute toxicity of cyanide in aerobic respiration: Theoretical and experimental support for murburn explanation. Biomol. Concepts 11:32-56 (2020a).

20. Manoj, K. M. et al. Atypical profiles and modulations of heme-enzymes catalyzed outcomes by low amounts of diverse additives suggest diffusible radicals' obligatory involvement in such redox reactions. Biochimie 125, 91-111 (2016b).

21. Manoj, K. M. et al. Chemiosmotic and murburn explanations for aerobic respiration: predictive capabilities, structure-function correlations and chemico-physical logic. Arch. Biochem. Biophys. 676, 108128 (2019b).

22. Manoj, K. M. et al. Cytochrome P450 reductase: a harbinger of diffusible reduced oxygen species. PLoS One 5, e13272 (2010).

23. Manoj, K. M. et al. Electron transfer amongst flavo- and hemo-proteins: diffusible species effect the relay processes, not protein-protein binding. $R S C A d v$. 6, 24121-24129 (2016a).

24. Manoj, K. M. et al. Functioning of microsomal cytochrome P450s: murburn concept explains the metabolism of xenobiotics in hepatocytes. Front. Pharmacol. 7, 161 (2016c).

25. Manoj, K. M. et al. Is Z-scheme a tenable explanation for the light reaction of oxygenic photosynthesis? OSF Preprints (2020c). doi: 10.31219/osf.io/v6tdf.

26. Manoj, K. M. et al. Murburn precepts for the light reaction of oxygenic photosynthesis and 
chloroplast homeostasis. OSF Preprints (2020b). doi: 10.31219/osf.io/95brg

27. Manoj, K. M. et al. Murburn scheme for mitochondrial thermogenesis. Biomed. Rev. 29: 73-82 (2018).

28. Manoj, K. M. Murburn concept: A paradigm shift in cellular metabolism and physiology. Biomol. Concepts 11, 7-22 (2020b).

29. Manoj, K. M., \& Tamagawa, H. Revisiting the mechanisms for cellular homeostasis and electrophysiological responses: Classical membrane theory, association-induction hypothesis and murburn concept. (2020). OSF Preprints. doi:10.31219/osf.io/e2ynk

30. Manoj, K. M. The ubiquitous biochemical logic of murburn concept. Biomed. Rev. 29:89-98 (2018b).

31. Manoj, K. M., Bazhin, N. M. The murburn precepts of aerobic respiration and homeostasis. $J$. Biomol. Struct. Dyn. (2021) doi: 10.1016/j.pbiomolbio.2021.05.010

32. Manoj, K. M., Parashar, A., Jacob, V. D., Ramasamy, S. Aerobic respiration: proof of concept for the murburn perspective. J. Biomol. Struct. Dyn. 37, 4524-4556 (2019a).

33. Milo, R. \& Phillips, R. Cell Biology by the Numbers. Garland Science (2015).

34. Nelson, D. L. \& Cox, M. C. Lehninger: Principles of Biochemistry $4^{\text {th }}$ edn. W H Freeman (2004).

35. Nicholls, D. G. Mitochondrial membrane potential and aging. Aging Cell 3: 35-40 (2004).

36. Okur, H. I. et al. Beyond the Hofmeister series: Ion-specific effects on proteins and their biological functions. J. Phys. Chem. B. 121, 1997-2014 (2017).

37. Parashar A., et al. Hemoglobin catalyzes ATP-synthesis in human erythrocytes: A murburn model. $J$. Biomol. Struct. Dyn. (2021). doi: 10.1080/07391102.2021.1925592

38. Parashar, A. \& Manoj, K. M. Murburn precepts for cytochrome P450 mediated drug/xenobiotic metabolism. (In Press) Curr. Drug Metab. (2021). doi: 10.2174/1389200222666210118102230

39. Parashar, A. et al. Cyanide does more to inhibit heme enzymes, than merely serving as an active-site ligand. Biochem. Biophys. Res. Commun. 455, 190-193 (2014).

40. Parashar, A., Gideon, D. A., Manoj, K. M. Murburn concept: a molecular explanation for hormetic and idiosyncratic dose responses. Dose Response 16, 1559325818774421 (2018).

41. Pollack, G. H. Cells, Gels and the Engines of Life. Ebner and Sons Publisher, Seattle. (2001).

42. Reza, M. E., Rashid, M. A., Haque, M., Pervin, F., Ali, L. Serum and intracellular levels of ionized sodium, potassium, and magnesium in type 2 diabetic subjects. Int. J. Nutr. Pharmacol. Neurol. Dis. 5:69-74 (2015).

43. Roy S., Baer M. D., Mundy C. J., Schenter G. K. Marcus theory of ion-pairing. J Chem Theory Comput. 2017 Aug 8;13(8):3470-3477.

44. Scott, J. A. \& Rabito, C. A. Oxygen radicals and plasma membrane potential. Free Rad. Biol. Med. 5; 237-246 (1988).

45. Spector, W. G.. Electrolyte flux in isolated mitochondria. Proc. R. Soc. London, Ser. B. 141; 268-279 (1953).

46. Stoin, U., et al. In situ generation of superoxide anion radical in aqueous medium under ambient conditions. Chemphyschem. 14; 4158-4164 (2013).

47. Tamagawa, H., Mulembo, T., Delalande, B., \& Manoj, K. M. Explaining trans-phase potential differences with membrane theory, association-induction hypothesis and murburn concept, OSF Preprints (2021). doi: 10.31219/osf.io/asrw5

48. van der Vegt N. F., Haldrup K., Roke S., Zheng J., Lund M., Bakker H.J. Water-mediated ion pairing: Occurrence and relevance. Chem Rev. 116:7626-41 (2016).

49. Vaughan, G., Przybylski, A. T., Fox, S. W. Thermal proteinoids as excitability-inducing materials. BioSystems 20: 219-223 (1987).

50. Voet, D. \& Voet, J. G. Biochemistry $4^{\text {th }}$ edn. Wiley (2011). 